\title{
Hit by a stroke - an autoethnographic analysis of intergenerational care across geographical distances
}

Marit Aure, marit.aure@uit.no

\begin{abstract}
Increased geographical mobility, improved medical treatment, and prolonged life expectancy have changed the way of life for older persons and their next of kin. This chapter discusses intergenerational care, mainly from the next of kin's point of view, when an older family member and the next of kin live far from each other. The study is based on my - the author's - autoethnographic account of the experience after my father suffered a stroke a few years ago. Inspired by Ellis et al. (2011, p. 392), who stated that autoethnography may 'analyse personal experience in order to understand cultural experience', I use my father's and my own experiences to analyse how geographical distance and serious illness impact intergenerational care and kinship. While I argue that intergenerational care across geographical distance creates certain vulnerabilities, this specific situation also enables and enacts kinship relations. The study focused on practical support, emotional relations, and communication technologies, and their limitations when illness hits and life changes. It also adds to our understanding of aging, illness, and care across vast geographical distances. I claim that the autoethnographic approach accommodates the subjectivity, emotions and first-hand experiences between the older person and the next of kin. This geography of intergenerational care provides new knowledge about an experience; influencing the later years, for an increasing number of individuals and serviceproviding municipalities, especially in regions marked by outmigration and high youth mobility.
\end{abstract}

\section{Vignette}

A week before our three-generation family group should leave for the long-planned pilgrimage hike in Spain, I received the alarming phone call. My father, the 'caring hub' of the family, was hit by a sudden and severe stroke. I went cold and numb, hurried into my office, called my husband, booked my flights, called for a taxi, left work, picked up some luggage at home, and went to the airport. During the two flights,my mind was racing with questions: How was he, would we lose him now, how would he become, who would visit and take responsibility for my chronically disabled mother now? A few hours later, my sister, who had arrived on an earlier plane, picked me up from the airport in our hometown and with tears in our eyes, we hugged and drove directly to the hospital. During the 10-minute drive, she updated me: he was conscious. He was not paralysed but had only said a few words. Through tears, we laughed: all the thoughts he tried to formulate transformed into the same words: ‘the company'. He obviously experienced aphasia. 
Arriving at the familiar small-town hospital, we went straight to the four-bed room. Dad looked tiny in the bed, as if he had shrunk. He was pale, and there was an 'emptiness' on his face. His features were childlike in the way he was sitting on the edge of the bed in the hospital pyjamas, his feet not reaching the floor. Yet, despite lacking words and experiencing aphasia, he was also clearly himself. He was vulnerable, ill, and insecure like we were, but still with us. My sister and I walked to his apartment and talked about practicalities, our anxiety, and his whereabouts and what had happened this morning when the stroke hit him. What would happen now, how long could we stay? We were acutely aware that we were both visiting from distant places, as we had our lives, jobs, families, and friends miles away.

Nevertheless, we were also aware that our father's economic situation, and the flexibility of our jobs placed us in a privileged position. However, we still had to deal with the fact that there were no relatives in the geographical proximity. Our lives changed.

\section{Introduction}

Geographical distance and limited possibilities to obtain help from family members are sources of great concern and low subjective well-being among older persons (Slagsvold et al., 2012, p. 101). The increasing number of older persons living alone is of particular concern, 'because the availability of kin support largely depends on geographical accessibility and social contact' (Hank, 2007, p. 158). Demographic changes, such as long life expectancy, long shared lives between adult children and parents, and increasing societal complexity thus shape the life and well-being of older persons (Bengtson, 2001). Furthermore, this has made multigenerational ties increasingly more important in the $21^{\text {st }}$ century and requires the understanding of diverse forms of care beyond the nuclear family (Bengtson, 2001). According to Connidis (2010), this underlines the importance of exploring the qualitative aspects older persons’ family relations. While paid care services may compensate for diminished intergenerational care, care is also a question of family obligations and moral expectations (Svašek, 2008). Even in Scandinavian countries, where the welfare state plays an important role in care for older people, data suggests that the family-welfare state balance in elder care is around 50-50 (Slagsvold et al., 2012, p. 
100). Intergenerational care is thus highly important. The significance of geographical distance and intergenerational care becomes particularly visible when severe illness occurs, and the older family member and the next of kin live far from each other. Intergenerational care across distances is common in rural and peripheral communities that experience young persons' out migration but may influence the lives of older people and their next of kinin many communities. Thus far, however, scholars have paid little attention to the geography of informal intergenerational care. This chapter deals with severe illness of an aging parent across vast geographical distances and focuses on the production and provision of kinship and informal care, emotions, communication technologies (ICT) and practicalities in everyday life, and their limitations. I ask how geographical distance affects my practice and experiences as a next of kin, and how this impacts my father and my relationship with him.

\section{Intergenerational care - concepts and approach}

Intergenerational care and aging across geographical distances intersect in several ways. Already Parson in 1943 (as cited in Hank, 2007, p. 158) suggested that increased geographical distance could reduce the interaction between children and older parents. Others have acknowledged the adaptability of kin networks and argued that kinship interaction will occur despite geographical distance, while also recognising the negative effect of geographical distance on the possibilities for intimate and affective intergenerational interaction (Hank, 2007). In this approach, geography and social contact constitute a basic opportunity structure for intergenerational interaction (Bengtson, 2001, p.8).

However, intergenerational care is also performed between persons who see themselves as belonging to each other through kinship (Drotbohm \&Alber, 2015, p. 7). This perspective argues that kinship is not given, but is mutually created through care, social interaction, and subjective interpretation. Therefore, kinship constitutes but is also constituted by care. Furthermore, intergenerational care is often described as an exchange, which may shift during the life course, of providing and receiving care (e.g. Silverstein \& Giarusso, 2010). A performative perspective on care challenges the one-directional relationship of giving or receiving (Drotbohm \& Alber, 2015) and highlights that caregiving is also care-receiving, (Weicht, 2015) as it holds both costs and rewards (Raschick \&Ingersoll-Dayton, 2004). Kinship is hence 
dynamic, produced through intergenerational care; care maintains and affirms kinship, but also strain and challenge kinship ties and the content of care (Drotbohm \&Alber, 2015).

Social care covers a broad range of activities such as 'providing personal care, doing household chores, preparing meals, shopping, taking care of finances, providing companionship, checking up regularly, arranging and supervising activities and outside services, and coordinating medical care’ (Silverstein \& Giarusso, 2010, p. 1047). Distinguishing between formal (obtained in a private or public market) and informal care, Rosenthal (2007, p. 755) includes managerial care, referring to 'carerelated discussions [...] about the arrangements for formal services and financial matters, doing relevant paperwork, and seeking information', as an aspect of informal care. Rosenthal's (2007) survey describes the prevalence of such an arrangement, and how it may create stress for caregivers, but provide limited information about the practice, recipients' experience, rewards, and emotions, and how this is tied together in individuals' lives.

While these studies specify and discuss the content of diverse care practices, the social support framework (House, 1981) categorises care based on its functions: a) Emotional support based on shared experiences offers love, concern, trust, empathy, etc. and shows value; b) Tangible or instrumental support provides financial or physical assistance, material goods and services, and encompasses direct assistance; c) Informational support provides advice, guidance, and information; and d) Companionship supports social belonging through shared activities. These categories may overlap and involve several functions as well as representing an analytical tool. Later studies have criticised the distinction between providing, perceiving, and receiving, and between intentions and results among the various actors (e.g. Thoits, 2011).

I have reformulated the social support framework to focus on practices and experiences and to align it with the 'doing' of care and the performative perspective that underlies this study. Care is hence seen as the emotional interaction, assistance, guidance and information sharing, which make care become a shared activity. However, neither of these perspectives discuss the geography of care and support, and 
geographical proximity seems to be rather taken for granted. Before turning to a short discussion of age, I will briefly present a relational approach to the intersection of care and geographical distance and ICT.

A relational approach to place sees geographical distance and space as resulting from and co-constituting practices and interrelations (Massey, 2005). This approach to the production of space (Lefebvre, 1991) conceptualises space as a dimension of social practice, rather than a condition or an opportunity structure. Within such perspective care is spatial. Adding a mobility perspective further highlights spatial diversity, makes mobility visible, and 'normalises' the existence and variety of mobile lives (Sheller \& Urry, 2006; Walsh et al., 2013).The emerging literature on the geographical circulation of care has also discussed care across generations and life courses (Assmuth, 2013;Assmuth and Lulle, 2013; Baldassar and Merla, 2013;Siim, 2016; Svašek, 2008).The strain of generational care has highlighted emotions in mobile lives (Aure 2018; Hondagneo-Sotelo and Avila 1997; Parreñas, 2001).

In line with a performative perspective, ICT has an effect on the webs of relations and is produced by these webs (Law, 2009). Older persons, next of kin, care, and their interconnections are produced by ICT, while they also 'produce' ICT through care, kinship, situations, and networks. This perspective is not only concerned with the digital divide among older persons, which is observed between pre- and post-Second World War cohorts (Gilleard and Higgs, 2008), but also highlights the role of ICT in ageing. ICT inevitably produces both age and age-related disabilities, has certain agerelated effects, compensates for age-related problems (e.g. hearing aids, audio-books), and obtains new meaning (becomes something else) when being used by older persons and kin in specific situations. Similarly, ICT may overcome geographical distance, but also creates the need for face-to-face interaction and help (e.g. to maintain internet services, understand new program updates.). Performative perspectives shift the focus from understanding aging in terms of specified categories to understanding the processes of aging through intergenerational care, and intergenerational care through the dynamics of aging.

Age is core to intergenerational care, and as more individuals are living longer, aging becomes more heterogeneous, and the anticipated chronological coherence in later life 
is questioned (Gilleard \&Higgs, 2013). In trying to understand this heterogeneity, the concept of 'third age' divides between an active and healthy old age and the' fourth age's 'old old', characterised by increasing medicalisation, ill-health, and corporal inability (Gilleard and Higgs, 2017). However, while Gilleard and Higgs (2017) connect the third age to a cultural generation rather than an age cohort, the distinction between 'ages' serves to make these 'ages' mutually exclusive and additive- the unhealthy fourth age follows the healthy third age. This hides the asymmetrical and blurred transitions between 'ages'. According to Gilleard and Higgs (2017), the division between the fit and the frail is a major source of social division among older persons, rather than solely resulting from differences in class, gender, and sexuality. They have argued for a focus on corporeality: the disabled and able body, and illness are important in understanding diversity, exclusion, and civic engagement in later life. However, their distinction between 'ages' draws the focus away from the intersection between the cultural generational lifestyle of the third age and the frailty that may also affect individuals in the third age.

Moreover, this perspective pays limited attention to cognitive functions, whether these result from physical inabilities or are subsumed in the concepts of corporality or frailty. The 'moral imperative of care' prevents exclusion from the relations of the wider society and tie the elder to the social world, as Higgs and Gilleard (2015, p. x) rightly point out in the case of the 'old old'. Gilleard and Higgs (2017, p. 1682) connect this with becoming 'too old'. I suggest seeing illness as an inevitable part of aging and distinguishing 'ages' even more from chronological ages. This requires an analytical use of the concept of the third and fourth ages, rather than connecting it to 'too old' and 'old old', which are concepts basically based on chronological age, with the third age thus being followed by the 'too old' fourth age.

The performative perspectives on kinship, care/support, geography, ICT, and age and illness suggested here make it possible to discuss a wide variety of intergenerational care practices in order to obtain a better understanding of the geography of intergenerational care through a first-hand account of the experiences of an older parent's severe and sudden illness. The aphasia that my father developed as a result of his stroke was a central part of this experience. 
The chapter proceeds with a brief presentation of autoethnography, a controversial method (Langdridge, 2016) due to its subjectivity, accusations of being anecdotal, and its occasionally unconventional forms. I then present a narrative of our experiences from the period when the stroke occurred until today, and discuss themes that have become vital in our experiences, including the important role of ICT in modern societies and in relationships across geographical distances.

\section{Methods}

I apply autoethnography to tell this story from my, the next of kin's, point of view. Further, I include my father's experiences, as he expresses them in our frequent talks and reflections about this experience. Autoethnography may 'describe and systematically analyse personal experience in order to understand cultural experience' (Ellis et al., 2011, p. 392), and hence through 'displaying multiple layers of consciousness, connecting the personal to [the] cultural' (Ettorre, 2005, p. 536). Autoethnography encompasses a variety of forms, including fictional tales, biographical or autobiographical narratives, poetry, and reflections. Even if there is a tradition of presenting a distinction between evocative and analytical practices (Anderson, 2006), I emphasise how they may be simultaneously personal and scholarly, evocative and analytical, descriptive and theoretical (Denshire, 2013).

The main idea of autoethnography is that personal narratives can address key theoretical debates in sociology, as they may provide access to the individual and the social, making it possible to see connections between them (Laslett, 1999, p. 392). This method can accommodate the subjectivity, emotions, and relationship between the older person and next of kin, which are useful for understanding experiences of serious illness (Ellis et al., 2011). According to Anderson (2006), autoethnography offers access to rich data on specific themes. Access to insiders' views, is a personal dimension adding a vantage point that otherwise can be missed and may evoke emotional resonance.

However, one main critique is that autoethnographic accounts leave it to the reader to analyse the data and add the conclusions to a broader understanding: 'to gain insight into some broader set of social phenomena than those provided by the data themselves' (Anderson, 2006, p. 387). Another critique is that such narratives only 
present personal experience and fail to actually 'transform given personal experiences (...) into ethnographic writing' (Archetti, 1998, p. 215, my italics). Autoethnography challenges the subject-object distinction in research. Some researchers find this problematic, because they value a sense of objectivity (Denshire, 2013). Anderson (2006) argues that an analytic autoethnography has to (1) be conducted by a researcher who is a full member of a research group; (2) include analytic reflexivity; (3) include narrative visibility of the researcher's self; (4) involve a dialogue with informants beyond the self; and (5) be committed to theoretical analysis. He adds that these key features make analytic autoethnography 'simply a specialised subgenre of analytic ethnography' (Anderson, 2006, p. 388). Contrary to this, evocative and emotional autoethnographies may be based solely on the writer's experiences with no explicit theoretical references or analytical perspectives, such as Ellis (1996) and Kelley and Betsalel (2004).

I am a full member of the research community and will reflect analytically on my own and my father's experiences. I am visible in these narratives, include dialogs with my father as data, and frame my discussions within current theories. I acknowledge that my father's voice is ‘filtered through the writer's voice’ (Davis \&Ellis, 2008, p. 287), but refrain from a traditional explicit discussion that relate our experiences to the theoretical framework and findings from other studies to keep emotional and evocative elements in the text. Even if I align with most of Anderson's (2006) requirements, I value the challenge of the object-subject distinction and the focus on lived experience that evocative autoethnography represents. Conversely, I find evocative contributions (e.g. Ellis,1996; Kelley and Betsalel, 2004) that escape all of Anderson's (2006) points, highly analytical in their approach and effect.

After discussing intergenerational care with people around me, I believed I could obtain similar data through qualitative interviews. It is nevertheless my first-hand experiences and the emotional relationship with my father that steered this research project, the process of discovery and hence the knowledge production. Applying an autoethnographic method makes this visible and accounts for the actual research process. My aim is hence to provide an analytic and evocative autoethnographic account (Williams and Zaini, 2016). My father fully consented to this project, and knows, understands and explicitly stated that he is aware that he can withdraw from 
this any time. Moreover, my mother, sister, and brother have given their consent to me writing this chapter.

This account is based on my experiences and conversations primarily with my father as I have remembered them. I have drawn upon notes taken during and after conversations (e.g., face-to-face, phone, Skype, FaceTime, chats, e-mail, and Messenger communications) with my father. I also video-recorded one of my own reflections on my mobile phone for the purpose of this chapter.

The implicit analysis, shown partly in the framework and contextualization and partly in the course and content of the narrative is based on what I and my father discussed and considered to be important. Thus, the performative approach to care and kinship, geographic distance and ICT, the social support framework, my special attention to geographical distance represent part of the analysis. When first discussing writing about my father's illness and caring at a distance, he stated that he found the project interesting and this became a recurrent theme in our conversations. He and I both suggest themes and experiences that we found to be vital, and this endeavour made us reflect more explicitly on our experiences together. Following the social support framework, I started with care as emotional interactions, followed by tangible care as assistance, care as informative guidance, and care as shared experiences. ICT is a theme throughout the chapter, not only under the information section, because it permeates many aspects of communication across geographical distances.

\section{Emotions-being together apart}

My father's and my first shared experience regarding his illness, which, still more than 3 years later, generated the strongest emotions, was the shock of my father suffering a stroke. It was a shock that lasted for days, and a shared experience only insofar it followed from the same incident and much of our later talk gravitates around it. Otherwise it was hardly a shared experience; he suffered the stroke- - he was in pain, dizzy, lost some of his right eyesight, could not coordinate his body's movements. He lost his ability to speak and understanding to an unknown degree, was afraid, and totally lacked knowledge about his future. 
My sister and I cried, laughed, and were angry when we were not with our father. However, when we were with him, we pulled ourselves together: we knew it was our responsibility now; we shared the frightening experience and the shock, and we were there to comfort him, be hopeful, and make sure he felt as secure as possible. We experienced relief when we found it was going to work out: he got to the hospital immediately and was on his feet again the same day. We were together and would manage. In one of the first planned meetings with his team of physicians and caregivers,I suddenly started to cry and could not stop. I realised that I was an orphan — with both my parents alive. Our family’s experiences with my mother's disabling stroke 15 years before made it clear that my father, the caring hub in the family, who visited our mother at the institution where she lived several times a day, was now in need of our care. My sister and I were now in charge of both of them. I was happy to have him, still I had lost my dad and was afraid he would never return. I was lost.

None of us lived there. My brother was the last to arrive and stayed for a couple of days. In the first meeting, the physicians asked about the next of kin and were surprised to learn that we were three siblings who all lived between 600 and $1350 \mathrm{~km}$ away. In the region where my father lived this meant no trains, days by bus or car, or more expensive air travel. It became evident, on that first trip, when my brother needed to help my father pack his suitcase for the stay in a rehabilitation centre: Nobody would be there to see him off. It was as if he had no next of kin to care for him. I was helpless. I value the welfare system that would care for him, but felt guilty for having moved away, for not being nearby and able to help. It felt like he was a person without people that loved him. The siblings talked, justified our livelihood and the choices that had led us away from our childhood town: our parents always wanted us to enter higher education and find our own way. They had themselves moved from their homeplaces. While my parents lived approximately an hour and a half by car from their parents, none of their children would be nearby to care for them.

\section{Caring at a distance}

The following days revolved around the calls to my father's mobile phone. Would I reach him today, would he pick up, and when he did not, was it because he had trouble with his phone, had forgotten the pin code, fell ill, or, what I feared most, was 
too depressed and did not want to talk? Trying to read his mood through the calls, be supportive, share his worries, be empathic but also balance his criticisms and negativity towards the rehabilitation drained me. I wanted to visit. It was a relief to go there, to see him by myself and be able to help in person, and to hug and cry with him. We installed Skype, brought an iPad the speech therapist had required for his speech training, shared the login details with the family via e-mail, and practiced how to use FaceTime and Facebook chat-applications that made it possible to reach each other with a camera and in various ways. The iPad gave him access to his newspapers, and even though he could not really read them, the surfing gave him some comfort in terms of getting an idea about what was going on, something to do, obtain a sense of normality, as well as shortening the time. The iPad meant freedom and allowed my sister to help him pick out the right shirt for a special occasion.

This visit was by far the most expensive part of his sudden illness. It required a hotel, a rental car, and long and complicated air travel. I spent far more than when taking my own nuclear family on a holiday to another continent. It felt grateful and a sense of relief to know that my parents were able and willing to contribute financially to this travel. I experienced further strong feelings of gratitude regards my family situationadult children, a caring husband, and favourable economic conditions. These conditions made it possible for me to spend time and energy with my dad. I appreciate our relationship, which involves few tensions, and makes me more patient with him than any other person. I feel thankful that our emotionally close and continuous contact was possible due to the freedom I experience at work, which allows me to work remotely, stay with my dad, visit my mom, and coordinate and organise numerous practicalities. I am suddenly vulnerable and dependant and have so much to be grateful about. The presence, often on Skype, being together on camera, are probably the most important experiences we shared in this period: I spent hours on the phone and Skype with him, going through what happened when the stroke occurred: How was my mother, did we (the siblings) manage to take care of all the arrangements she was entangled in? How was he, how would he manage, what about the language, the driving license that he lost because of the stroke? Mainly through ICT, I could share his worries, was hopeful, recalled the progress, and assured him that things would settle and become ok. These exchanges, which we both recognised 
and talked about were valuable and necessary, sometimes overly affirmative, spanned a fabric of love and concern that tied us together.

\section{Embodied emotions}

The short video I recorded about 4 months after his stroke, reminded me that the strongest emotions are maybe also the easiest memories to forget: Listening to my own voice, I remembered feelings I had totally forgotten, I said: 'Today is the first day I feel the sting in my chest. My lungs hurt and prickle and tingle in my thorax. Then, I think, this is to immerse myself too much in my father's life'. Did I choose to forget this?

About a year later, talking on Skype about this project and the progress with my writing, he said that the most difficult thing for him was the loneliness and the invisibility of his illness. With his ICT-device laying on the table, I could see only the top of his head, sitting in his living room. I knew that he does this familiar gesture, massaging his eyes and patting his eyebrow. His loneliness hit me, my guilt felt cold. I was not there. He was alone. The aphasia has taken away his long hours of reading and TV-watching, and made him afraid that his speech doesn't make sense. He has become restless and anguished, and when walking on the street, the people he met do not know. It does not show, but when he stopped and talked to acquaintances, he felt that when they heard the words fail him, they thought he has 'lost it'. He has become insecure. Even though he has learned to talk about the stroke and the aphasia, most people have forgotten, and he found it shameful not to be able to understand them, to miss information, and not be able to respond adequately. My heart bled for him. I have told him how sorry I am: for him being alone; for me being far away, and he has comforted me and we shared a moment of sorrow and of thankful companionship, for sharing this.

Another set of bodily emotions brought us down new paths and amusing experiences. I felt creative when his chest pain, atrial fibrillation and anxiety about his heart made me suggest trying to do yoga together - apart. After some time, he was willing to try 'just to test it', as I assured him. We started using yoga instructional videos on the iPad. When visiting him, I would find videos and create shortcuts, and we would practice yoga/stress release exercises. This was a totally new experience for him, and 
an intimate experience for me to do yoga with my dad. We joked about how we almost went to extremes to deal with the new situation. A few days later, he could not find the videos, but I could guide him using my voice and the cameras on several devices until we found the programs. The open mindedness of this former self-made businessman and accountant from a rural non-academic background made me proud. However, the technology also made us share some frustrations. For instance, the many login usernames and passwords, the various problems regarding changing internet connections, installing new programs on his PC, mobile phone, and iPad, and new drivers for the printer caused swearing and anger, and required assistance from children, children in law, grandchildren, and professional help.

\section{Tangible practices, geographical proximities and digital strategies}

The tangible and instrumental care practices dealt with my father's financial help towards us, how we assisted him physically, and the exchanges of services and material goods. Help with the technology, the software, and the access and function of the software has been necessary to be able to receive private and public documents and instructions. Extra problems have occurred when information arrived in long formal letters, or in English, when the aphasia and lack of English knowledge has made him helpless. Digital communication with most private and public services requires writing, reading, and login procedures with 'tons' of passwords. The digitalization and aphasia has made him disabled while ICT also has become a tool for remote assistance. It has enabled the family to share information, keep an electronic e-mail diary with the information necessary to assist in practical day to day activities, and show daily concerns. This engagement produced a feeling of mastering and care, but for him, as he said, also an experience of being left behind, dependent on others.

Living in the centre of a small town with most services at walking distance made my dad able-bodied even though he felt restricted when his driving license was cancelled. 'The problem is here', he would say and point to his head. Physical concrete support was not his main need, and his financial position made him used to and able to buy cleaning services and eat out. Luckily, even if he sometimes was unable to recall the pin codes for his different cards, his fingers remember them and ensures his ability to 
withdraw cash and pay in the stores. New ATMs or other services could contribute to stress and fatigue, which would make him embarrassed and both of us aware of his vulnerability in new situations. The aphasia required him to develop new strategies.

Talking on the phone with strangers has become out of the question, this forces him to show up at the counter to set up doctor's appointments. Furthermore, the aphasia also made the visits at the doctor's office difficult. He would be worried about his medical results and the consequences for the coordination of the medication that were administered by the public home health service. He found himself unable to articulate to the doctor how he feels and tell about problems and pains. He could not convey the doctor's information and retell it to me. The tangible assistance of calling the doctor after his appointments to obtain information, became problematic since it required formal written consent. We hence scheduled appointments when a family member is present, or dad would call up and bring me into the conversation using the loudspeaker on his phone during the session. He would do the same when he needs help in shops, or making travel arrangements. This remotely facilitated practical direct assistance, almost as if I were physically present, and thus enabled us to later talk about the results and the particularities of his daily doings.

Certain incidents or sudden health problems are hardly manageable remotely. When father falls ill and needs help to get to the hospital, we are unable to assist him. He has been forced to make agreements with friends. We all know that this is a second-best solution for him, who actually has a family. This is the weight of practical and moral expectations and discomfort inherent in intergenerational care. Some digital services also require physical presence, although the camera on his devices has made it possible to assist him on some practical issues remotely. In order to compensate for the loss of reading and to help with his feelings of loneliness and restlessness, we wanted to install an audiobook application.

Going through the installation procedure on his devices while communicating using sound and camera, the procedure asked him to print a form, take it to the audio therapist for a confirmation and signature, and then mail it to a national service, stopped us. At the time, he was unable to print from his iPad and would have problems writing the right address on an envelope. After some time and visits, as well 
as phone calls to the national service, and ultimately installation of the application, 'reading' has once again become a dear leisure activity. Who can help with these small daily problems?

\section{Informational support and guidance}

Paradoxically, living in a digital information society requires literacy. Even audio support is often based on written language and requires high levels of information processing, which are cognitive abilities typically damaged in patients with aphasia. Dad is able to use his computer, iPhone, and new software, but has experienced problems although he is accustomed to these gadgets from his professional life. The new digital services increasingly require personal logins, which may be hard to circumscribe. Conversely, information about changes in the charging system for his plug-in car and important medical information have arrived in the post, and in order to read this information, he needed to be able to install and update applications on his phone and send the scanned document to family members to read. We have spent many calls repeatedly going through the activities of the week, because he was worried that important information has escaped him in a letter or digitally. We have reviewed my parents' medical appointments, discussed news of interest, information about local health administration and provision, bank accounts, life and property insurance, new internet providers, changes in electricity systems, and welfare support-living in modern societies is complicated.

Right after the stroke, the primary contact person in the municipal health care service was supposed to coordinate and help. However, this person and the function changed several times during the first months following the stroke, and I was unable to follow and had to take notes to keep track of names and responsibilities in the municipality. The number of nursing assistants who provided medicines and care in periods of illness was uncountable. Double that when I included my mother's more complicated health condition and divided the responsibilities a little to account for the help between the siblings which was coordinated and divided between us through Facebook groups, and family chats during visits to make it manageable. This management need has stabilised on a lower lever as time goes by. It feels, however, as if it has been replaced by the need for companionship and social belonging. 


\section{Companionship and shared activities}

Looking through my notes from our conversations, I found that dad has problems finding words maybe 10-20 times during a 20-minute chat. This exceeded my expectations, perhaps because I need to feel hopeful, my familiarity with his language, the themes, and that the context has helped me understand. I believe him when he talks about how-this being a social problem. It has however not prevented him from meeting people and seeking out new activities.

Bravely he joined a Tuesday afternoon exercise class, and the weekly technology class for older persons after he became ill; however, he shared that he gets tired of concentrating and becomes aware of the mistakes and blunders he has made in front of acquaintances and strangers. He knows that he needs these activities in order to meet people, as he has said "I cannot be alone the whole day". Moreover, hhile, he explained, older women pay each other visits for coffee and chats, older men are not that good at socializing. He, however, still sees his former network of businessmen for lunch every day and has dined at the municipality health care centre. These issues turn up when he is stressed and are recurrent themes in the chats between us-How I wish I were there to be together and share his life!

My frustrations sometimes come out as irritation and hurt, and I am glad to know that I can share them with the family and that we are able to laugh and let steam out. I could join him for his daily walk, we could go to the cinema or concerts, do errands, have a quick cup of coffee, share with him details of his grandchildren's performances. These are activities that are beyond everyday contact and messages, mails, calls, and pictures on all kinds of digital platforms. We have planned for hours and days the next holidays and family gatherings, and since he does not trust himself to go on longer trips alone, the family must coordinate to travel with him and help plan group travels. Father and I have talked these things through, we have discussed common experiences and experiences at our own ends. This has allowed him to practice talking, share, and make time go by-we both know it and talk about it. We value the camaraderie, but both also feel lonely. Some months after the stroke I introduced the issue of applying for a municipal service assistant. After getting used to the idea, we applied, and he was assigned a young man to keep him company. 


\section{Concluding words}

Concluding this chapter poses challenges. As I decided not to make the analysis explicit, I sum up this study by highlighting results that are demonstrated rather than analysed in a traditional way.

Drotbohm and Alber (2015) have argued that kinship is shaped by interaction and care. I find that the closeness and broad register of contact in the varied caring practises have intensified my relationship with my father. Kinship means more and the relationship redefines. Despite the fact that my active, healthy dad continues to help me economically, practically and in many ways through his intellectual capacity and broad knowledge gained through a long life in business and politics, his stroke did disturb the adult child-superior parent relationship. His need for help and care has made our relationship more equal, but also reminded us, that in this phase of life, he has become needier, and the parent-child relationship is under revision. Role reversals typically involve strong and contrasting emotions. This became obvious in my feeling of being orphan, and in the childlike features the illness imposed on him.

My father, I think, lost his independency and pride through the increased loneliness. We both have tried to secure his independence, but we also know and have talked about how this balance is changing. The thankfulness for our relationship is part of this check and balance, and I would suggest that keeping the idea of a superior parent status is an important element in the third age. This may be a defining and valued part in third-agers' self-esteem. Needing their children for more than companionship is thus a sign of getting old: part of the frailty that illness inflicts. This acceptance of becoming older and needy of your children's help is perhaps the hard part.

The problem is not to ask for help, nor that he think we cannot help, but the burden of recognizing that he needs more help than he is currently able to provide to others. He is definitely still part of the culturally defined third age (Gilleard and Higgs, 2017), and he currently attends seniors' choir, senior university, swimming and gymnastics, and travels. However, he has also been marked by the life-changing illness and becoming a fourth ager. This challenges the distinctions between the third and the fourth age, and the transition between these groups may seem blurred with illness, which is an inevitable part of aging. I suggest that aging should be understood as 
intersections of fit and frail, the corporal and the cognitive, and health and illness. This intersection requires distinguishing the third and fourth 'ages' even more from chronology.

The increased use of and reliance on ICT is integral in understanding intergenerational care at geographical distance. The increased administration and management of life expressed in the digitalized services, the numerous usernames, passwords and pin codes, and data support needed when there is no employer or professionals to keep you up to date, is vital in understanding aging. The account also shows the interaction of a multitude of variables including, the importance of companionship, the emotions involved in living with aphasia, gender and loneliness, the vulnerability involved when your main health problems are invisible but attack the speech centre, and new cognitive challenges related to reading and writing.

I have explored the entanglement of intergenerational care, aging, and ICT across geographical distances, but more than in traditional analytical texts, it is left to the reader to decide if this has been done adequately. The narrative demonstrates the firsthand experiences, the process of discovery and knowledge production, and how an autoethnographic approach may accommodate the subjectivity and emotions between the older person and their next of kin.

The autoethnographic approach also challenges the content of the narrative: The focus on the relationship between me and my dad suggested that there are few other people around, which is not he case. However, keeping it my story implies a limitation. This account may, therefore, prioritize the personal and individual at the cost of shared experiences.

Furthermore, I found it difficult to switch between evocative descriptions that required meticulous empirical proximity and a more distanced analytical writing, and created a not-too-evocative text with a rather implicit analysis. This tension between emotional proximity and a detailed account on the one hand, and the need for analytical distance, contextualization and structural accounts on the other may explain the choices made in the more evocative autoethnography (Ellis, 1996; Ellis et 
al.,2011; Kelley \& Betsalel, 2004). These studies are meticulously personal and evocative accounts without any explicit 'disturbing' analysis.

Maybe the combination of analytical and evocative autoethnography is hard to achieve, and what gets lost in a combined approach, is the closeness, emotions, and experiences, which is the very rationale for using this approach? What is gained is first-hand knowledge of everyday aging in situations that is becoming widespread and influencing an increasing number of individuals. Based on a personal account this brings knowledge useful for municipality and private services, especially in regions marked by outmigration and high mobility.

\section{References}

Aure, M. (2018) Mobile fathering: absence and presence of fathers in the petroleum sector in Norway in Gender, Place and Culture. doi:10.1080/0966369X.2018.1462769.

Anderson, L. (2006). Analytic Autoethnography. Journal of Contemporary Ethnography, 35(4), 373-395. doi:10.1177/0891241605280449.

Archetti, E. P. (1998). Auto/Ethnography: Rewriting the Self and the Social. Anthropological Quarterly 71(4): 215-217.doi:10.2307/3317445.

Assmuth, L. (2013). Asymmetries of gender and generation on a post-Soviet borderland. In J. L. Bacas \& W. Kavanagh (Eds.), Border encounters. Proximity and asymmetry at Europe's frontiers (pp. 142-163). Oxford: Berghahn Books.

Assmuth, L. \& Lulle, A. (2013). Families on the Move in Europe: children's perspectives. Siirtolaisuus - Migration, 3, 3-10.

Baldassar, L., \& Merla, L. (eds.). (2013). Transnational families, migration and the circulation of care: Understanding mobility and absence in family life. Abingdon, UK: Routledge.

Bengtson, V. L. (2001). Beyond the nuclear family: The increasing importance of multigenerational bonds. Journal of Marriage and Family,63(1), 1-16.

Connidis, I. A. (2010). Family ties and aging. California: Pine Forge Press.

Denshire, S. (2013) ‘Autoethnography’, Sociopedia.isa, doi:10.1177/205684601351.

Davies, C. S. and Ellis, C. (2008). Emergent methods in autoethnographic research. autoethnographic narratives and the multiethnographic turn. In S.N. HesseBiber, P. Leavy (eds.), Handbook of emergent methods (pp. 283-302). New York: The Guilford Press. 
Drotbohm, H., \& Alber, E.(2015). Introduction. In E. Alber, \&H. Drotbohm (Eds.), Anthropological perspectives on care. Work, kinship, and the life-course. New York: Palgrave Macmillan. (pp. 2-21)

Ellis, C. (1996). Maternal Connections. In C. Ellis \& A. Bochner (Eds.), Composing ethnography: Alternative forms of qualitative writing(pp. 240-243). Walnut Creek, CA: AltaMira Press.

Ellis, C., Adams, T. E., \& Bochner, A. P.(2011). Autoethnography: An overview. Historical Social Research-Historische Sozialforschung, 36, 273290. doi:http://nbn-resolving.de/urn:nbn:de:0114-fqs1101108.

Gilleard, C., \& Higgs, P. (2017). Ageing, corporeality and social divisions in later life. Ageing and Society, 37(8), 1681-1702.

Gilleard, C., \& Higgs, P. (2008). Internet use and the digital divide in the English longitudinal study of ageing. European Journal of Ageing,5(3),233.

Gilleard, C. \& Higgs, P. (2013). The fourth age and the concept of a 'social imaginary’: A theoretical excursus. Journal of Aging Studies,27(4),368-376.

Hank, K. (2007). Proximity and contacts between older parents and their children: A European comparison. Journal of Marriage and Family, 69(1), 157-173. doi:10.1111/j.1741-3737.2006.00351.x

Higgs, P., \& Gilleard, C. (2015).Rethinking old age. Theorizing the Fourth Age. New York: Palgrave Macmillan.

Hondagneu-Sotelo, P., \&E. Avila. (1997). 'I'm here, but I'm there': The meanings of Latina Transnational Motherhood. Gender \& Society,11(5), 548-571. doi:10.1177/089124397011005003.

House, J.S. (1981). Work stress and social support. Reading, Massachusetts: Addison-Wesley.

Kelley, H., \& Betsalel, K. (2004). Mind's fire: Language, power, and representations of stroke. Anthropology and Humanism, 29(2), 104-116.

Langdridge, D. (2016). Recovery from heart attack, biomedicalization, and the production of a contingent health citizenship. Qualitative Health Research. https://doi.org/10.1177/1049732316668818

Laslett, B. (1999). Personal narratives as sociology. Contemporary Sociology, 28(4), 391-401 http://www.jstor.org/stable/2655287.

Law, J. (2009). Actor network theory and material semiotics. The New Blackwell Companion to Social Theory, Blackwell Publishing Ltd. 141158.https://doi.org/10.1002/9781444304992.ch7

Lefebvre, H. (1991). The production of space. Oxford: Blackwell. 
Massey, D. (2005). For Space. London and Thousand Oaks. New Dehli: Sage.

Parreñas, R. S. (2001). Mothering from a distance: Emotions, gender, and intergenerational relations in Filipino transnational families. Feminist Studies,27(2), 361-390. doi:10.2307/3178765.

Raschick, R., \& Ingersoll-Dayton, B. (2004). The costs and rewards of caregiving among aging spouses and adult children. Family Relations, 53(3), 317-25.

Rosenthal, C., Martin-Matthews, A., \&Keefe, J. (2007). Care management and care provision for older relatives amongst employed informal care-givers. Ageing and Society, 27(5), 755-778

Sheller, M., Urry, J. (2006). The new mobilities paradigm. Environment and Planning A: Economy and Space,38(2): 207-226. doi:10.1068/a37268.

Siim, P. M. (2016). Everyday practices of translocal families: Estonian children and a sense of being-in-place. Ethnologia Fennica,43, 12-27.

Silverstein, M., \& Giarrusso, R. (2010). Aging and family life: A decade review. Journal of Marriage and Family, 72(5), 1039-1058.

Slagsvold, B., Veenstra, M., Daatland, S. O., Hagestad, G., Hansen, T., Herlofson, K., \& Solem, P. E. (2012). Life-course, ageing and generations in Norway: The NorLAG study. Norsk Epidemiologi,22(2), 95-102. doi:10.5324/nje.v22i2.1554.

Svašek, M. (2008). Who cares? Families and feelings in movement. Journal of Intercultural Studies, 29(3), 213-230.

Thoits, P. A. (2011). Mechanisms linking social ties and support to physical and mental health. Journal of Health and Social Behaviour,52(2), 145-161.

Walsh, D., Valestrand, H., Gerrard, S., \& Aure, M. (2013). Gendered mobilities in the North: Advancing an international comparative perspective. Norwegian Journal of Geography,67(5), 260-265. doi:10.1080/00291951.2013.847857.

Weicht, B. (2015). The meaning of care: The social construction of care for elderly people. Hampshire: Palgrave MacMillan.

Williams, J. P., \& Jauhari bin Zaini, M. K. (2016). Rude boy subculture, critical pedagogy, and the collaborative construction of an analytic and evocative autoethnography. Journal of Contemporary Ethnography, 45(1), 34-59. doi:10.1177/0891241614549835. 